\title{
La lematización de voces homónimas en los diccionarios actuales del español
}

\author{
Hermógenes Perdiguero Villarreal \\ Universidad de Burgos
}

Tras una rápida consulta al Diccionario de Autoridades podemos observar cómo una misma expresión tiene tantas entradas o lemas como acepciones; por ejemplo, podemos comprobar las nueve entradas -excluyendo las locuciones y frases- que el citado diccionario ofrece del vocablo razón o las cuatro entradas que presenta de la voz raya. En cambio, la última edición del diccionario académico (DRAE-92) incluye en una única entrada las quince acepciones que registra de razón, mientras que de raya encontramos dos entradas, porque sus étimos son distintos (radia / raia) ${ }^{1}$.

Según B. Quemada (1967: 272-465), fue ya en el siglo XVIII cuando surgieron dudas sobre la orientación monosémica de los comienzos de la lexicografía monolingüe y, poco a poco, se abandonó la idea de dedicar una entrada a cada acepción para, en su lugar, seguir el principio de agrupar los contenidos bajo una única entrada.

Pero el desarrollo y prestigio de los estudios etimológicos e históricos durante el siglo XIX tuvieron su reflejo en los diccionarios: así, la Real Academia Española -tras eliminar en la edición de 1869 las co-

1 Aprovechando la posibilidad de consulta de las distintas ediciones a través de Internet que facilita la Real Academia, se puede comprobar lo ocurrido en el caso de raya: las cuatro entradas del Dicc. de Aut. se reducen a una en la edición del DrAE de 1791; las tres ediciones siguientes presentan varias entradas $(6,6,5)$; en las cinco siguientes (de 1832 a 1869) sólo hay una entrada; y, coincidiendo con la introducción de la etimología de las palabras, desde la edición de 1884 hay dos entradas, diferenciadas por índices desde la edición de 1970.

Hermógenes Perdiguero Villarreal, "La lematización de voces homónimas en los diccionarios actuales del español", 
rrespondencias latinas- decidió incluir la etimología de las palabras en la $12^{\text {a }}$ edición de 1884 del DRAE. La influencia de la etimología en el diccionario académico se ve no tanto en la ordenación de las acepciones como en la diferenciación de aquellas acepciones de una misma expresión, que procede de étimos diferentes.

La existencia de diferencias tanto en los criterios como en las soluciones que se encuentran al respecto en los diccionarios actuales de español nos lleva a realizar una revisión del problema del tratamiento lexicográfico de las voces homónimas y polisémicas y buscar alternativas, teniendo presente que el quehacer lexicográfico ha de apoyarse en las distintas disciplinas lingüísticas, lo cual, según señala José A. Pascual,

explica que para realizar nuestro trabajo los lexicógrafos no podamos conformarnos con disponer de una vigilante intuición, si ésta no se apoya en el asidero metodológico que nos brinda la lingüística en sus diferentes campos (1996: 349).

\section{HOMONIMIA FRENTE A POLISEMIA EN LOS DICCIONARIOS}

El criterio etimológico empleado en la lexicografía académica no se está siguiendo en la lexicografía española actual, lo cual puede comprobarse en el caso de la citada voz raya en el Diccionario Salamanca de Santillana y en el Diccionario Escolar de Vicens Vives. No tendría mayor importancia este hecho si obedeciera a un principio debidamente justificado, aunque sólo fuera la idea de reducción del número de entradas que se plantearon los lexicógrafos del siglo XVIII.

El Diccionario de Español Actual de Seco, Andrés y Ramos (1999) proporciona entradas distintas de una misma expresión, pero no se apoya en la etimología para decidir la unidad o la diversidad de entradas, ya que sus autores entienden que un diccionario actual no debe actuar atendiendo a un criterio histórico. Como resultado de este planteamiento, encontramos dos entradas tanto para raya como para rodilla, separando, en esta última palabra, la acepción 'paño de cocina' del resto de acepciones. La decisión aplicada en este diccionario no se guía ya por 
la idea citada de economía de espacio, sino que parece apoyarse en un criterio semántico.

Tras comparar varias entradas del DRAE-92 con otros diccionarios actuales: el de M Moliner, el Vox-Alcalá-95, Salamanca, SMAvanzado-97 y el DEA-99, y, en efecto, se observan diferencias notables; entre ellas señalamos las siguientes, que aparecen reflejadas en el cuadro:

a) El DRAe y el Due incluyen dos entradas para banda y corte; VoXAlcalá, Salamanca y SM, una sola; el DEA, tres.

b) Para cava el DraE da dos entradas mientras que el resto de los diccionarios consultados incluyen una sola, excepto el de Seco que tiene cuatro.

c) El Drae y el Due dan cinco entradas para bote; el de Seco cuatro $\mathrm{y}$ el resto una sola.

d) Todos los diccionarios consultados tienen una única entrada para banco y banca, excepto el de Seco que da tres para cada una de estas voces.

\begin{tabular}{|l|c|c|c|c|c|c|}
\hline & banda & Corte & cava & bote & banco & banca \\
\hline DRAE-92 & 2 & 2 & 2 & 5 & 1 & 1 \\
\hline DUE-66/81 & 2 & 2 & 1 & 5 & 1 & 1 \\
\hline VOX-ALCALÁ-95 & 1 & 1 & 1 & 1 & 1 & 1 \\
\hline SALAMANCA-96 & 1 & 1 & 1 & 1 & 1 & 1 \\
\hline SM-Avanzado-97 & 1 & 1 & 1 & 1 & 1 & 1 \\
\hline DEA-99 & 3 & 3 & 4 & 4 & 3 & 3 \\
\hline
\end{tabular}

Con estos y otros datos se puede comprobar cómo el diccionario académico y el de $\mathrm{M}^{\mathrm{a}}$ Moliner tienden a separar los homónimos; el de SM toma la postura contraria: agrupa por sistema todas las acepciones en una sola entrada y en el interior del artículo explica el origen etimológico de cada una de las acepciones. El DEA de Seco, Andrés y Ramos es el que establece más entradas, aunque con criterios distintos a los del 
Drae. Los diccionarios Vox-Alcalá y Salamanca toman una postura intermedia, pero tienden a reducir las entradas.

Estas divergencias no son exclusivas de los diccionarios del español sino que son frecuentes en los diccionarios de otras lenguas. En relación con el tratamiento de la homonimia y de la polisemia, según Werner (1982: 298), Bergmann mostró hace unos años que existen divergencias considerables entre los distintos diccionarios del alemán y que, a veces, se encuentran bastantes incongruencias en un mismo diccionario.

\section{CRITERIOS DE DELIMITACIÓN}

Tradicionalmente la polisemia y la homonimia se han visto como dos fenómenos distintos: en el caso de la polisemia se habla de una misma y única palabra con varios significados, mientras que en la homonimia se distinguen dos o más palabras que convergen en el significante.

La distinción entre homonimia y polisemia ha sido replanteada, en especial, al tratar el tema del signo lingüístico. En la teoría lingüística, la homonimia y la polisemia tienen que ver con la plurivalencia de muchos de los significantes o, mejor dicho, con la plurivalencia de las realizaciones acústicas de una lengua dada. Según la definición habitual, en el caso de la homonimia existen dos o más signos con la misma realización acústica, mientras que en el caso de la polisemia se habla de un signo con varios significados o unidades de contenido.

El problema, cuando se ha planteado en relación con la elaboración de diccionarios, se ha centrado en la búsqueda de criterios que permitieran diferenciar uno u otro caso, siempre que se tratara de voces homógrafas, ya que las voces homófonas con diferencia gráfica (baca /vaca) se vienen registrando como entradas distintas, al igual que las palabras con doble grafía (armonía/harmonía; cinc/zinc; lubricación/lubrificación).

Los principales criterios, según Werner (1982: 300), han sido la etimología, la conciencia lingüística de los hablantes y la composición de 
los contenidos de las palabras, las cuales vemos a continuación junto con los criterios morfológicos.

\subsection{LA ETIMOLOGÍA}

En la práctica lexicográfica, en concreto en la relacionada con el español, la etimología ha sido y sigue siendo un criterio frecuentemente utilizado. El criterio etimológico es diacrónico y, para muchos, resulta ser el único método objetivo para detectar la homonimia: dos palabras serán homónimas si tienen un origen distinto; si tienen un mismo origen, nos encontramos ante una polisemia. En el primer caso estamos ante una convergencia diacrónica en el plano del contenido, mientras que en el segundo se ha producido una divergencia diacrónica.

Se han planteado algunas dudas sobre la adecuación de la orientación diacrónica en los diccionarios monolingües que pretenden realizar una descripción sincrónica de la lengua; posiblemente estas dudas son las que han llevado a Seco, Andrés y Ramos a no aplicar dicha orientación. Las críticas al criterio etimológico se apoyan en los casos en que no es posible determinar o demostrar convenientemente la etimología; incluso, puede suceder que la etimología de la palabra no refleje convenientemente el origen del significado, aunque muchas veces se entienda que la propuesta etimológica presenta un hecho de significado.

Teniendo en cuenta, además, que en la historia de las palabras se encuentran implicados hechos y procesos muy variados que pueden dar lugar a determinados significados el criterio de la etimología, defendido por autores como Ullmann y Baldinger basándose en la dicotomía saussureana sincronía/diacronía, no sirve para solucionar el problema.

\subsection{LA CONCIENCIA LINGÜÍSTICA DE LOS HABLANTES}

Para Ullmann (1964: 32) un diccionario sincrónico debe basarse en la conciencia lingüística de los hablantes, a diferencia del histórico, que se ha de basarse en la etimología. La delimitación de homonimia y polisemia sólo puede ser válida en un diccionario sincrónico si se realiza desde el punto de vista sincrónico y, además, se aplica el criterio de la conciencia lingüística de los hablantes. Según este criterio, estaríamos 
ante una homonimia cuando los hablantes no reconocen ninguna relación semántica entre dos acepciones de una palabra.

Sin embargo, no sólo la mayoría de los hablantes no reflexiona sobre la relación de los contenidos de una palabra, sino que, además, un hablante competente puede establecer la relación existente, incluso, entre contenidos muy alejados. Es lo que puede plantearse ante el caso citado de rodilla 'paño de cocina': mientras el diccionario de Seco, Andrés y Ramos, que incluye esta acepción en una entrada distinta, nos induce a separarlas, se ha podido aprender del Dech (s. v. rueda) su relación con la 'almohadilla circular que se pone sobre la cabeza para soportar peso'. Por lo tanto, este criterio no se puede utilizar con garantías suficientes si no se apoya en otros criterios, entre otras razones, porque no resulta fácilmente objetivable.

\subsection{LA COMPOSICIÓN DE LOS CONTENIDOS DE LAS PALABRAS}

La semántica estructural, con el fin de establecer una relación entre contenidos más objetiva que la que podía proporcionar la conciencia lingüística, se centró en el estudio de los elementos comunes de varios sememas. Se pensó que el análisis componencial del significado en semas ayudaría a diferenciar entre homonimia y polisemia: habría homonimia cuando los sememas de una misma expresión no tienen ni un solo sema en común, mientras que habría polisemia cuando los sememas tienen, al menos, un sema en común.

El criterio de semas comunes para distinguir homonimia de polisemia ha sido igualmente rechazado, bien porque es posible encontrar semas comunes a varios sememas, bien porque habría que analizar no sólo el semema que interese sino también todos los sememas que fueran relevantes para la determinación de los semas. Es decir, el problema se traslada al procedimiento de averiguación de los semas.

No obstante, el distribucionalismo pensaba poder dar una respuesta utilizando la distribución de las palabras en la frase como criterio para diferenciar significados. Pero esta alternativa no soluciona el problema, ya que una distribución diferente no tiene por qué responder necesariamente a una diferencia de significados. A pesar de ello se han elabora- 
do diccionarios, como los de Dubois ${ }^{2}$, siguiendo estos criterios. Su característica es la pronunciada tendencia hacia la homonimia.

\subsection{LOS CRITERIOS MORFOLÓGICOS Y SINTÁCTICOS}

Hay autores, como Pottier Navarro (1985: 44), que defienden la conveniencia de unir el criterio morfológico al semántico. En cambio, otros autores, como Lyons (1981: 148), manifestaron la necesidad de abandonar los criterios semánticos y basarse únicamente en criterios morfológicos y sintácticos, como la pertenencia a clases de palabras distintas, las series derivativas distintas, las diferencias de género y/o número y las valencias combinatorias diferentes.

Paul (1982: 298-299) cree, incluso, que los criterios morfológicos son los que permiten diferenciar la homonimia de la polisemia con mayor grado de precisión que los criterios semánticos. A este planteamiento se unen autores del ámbito de la semántica generativa como Leech (1985: 295-297), para quien las palabras inglesas: face 'cara' (nombre) y face 'ponerse cara a' (verbo) son dos piezas léxicas distintas y, por lo tanto, estamos ante un caso de homonimia.

De acuerdo con este criterio, el español cantar, verbo y nombre, deben declararse como dos voces homónimas al igual que (el) frente / (la) frente. En cambio, serían palabras polisémicas aquellas que difieren semántica o etimológicamente, como es el caso de real' 'verdadero', real 'relativo al rey o a la realeza', registradas en el DRAE-92 con dos entradas.

Diccionarios como Le Robert méthodique se han basado en la pertenencia a diferentes conjuntos de derivaciones como criterio para saber si hay homonimia. Esta solución atractiva que es la asignación a familias de palabras exige un análisis de los significados y, según Zöfgen (1989: 781), "ofrece menos soluciones objetivas de lo generalmente supuesto".

El DeA parece combinar el criterio gramatical con el de afinidad se-

2 DFC (1966), LEXIS (1975), NDFC (1980). 
mántica. Sus autores manifiestan expresamente el principio semántico ${ }^{3}$ que ha guiado su obra en el tema que nos ocupa:

El criterio aquí seguido ha sido el de considerar dentro de una misma entrada todas las formas iguales a las que une entre sí un mismo punto de partida semántico. En cambio, tratamos en entradas diferentes las palabras en que, pese a su identidad formal, no se tiene conciencia de una relación semántica (con independencia de que históricamente haya existido tal relación) (Seco, Andrés y Ramos 1999: XVII).

Sin embargo, subordinan el criterio semántico al gramatical, porque, como ellos mismos afirman ${ }^{4}$, han introducido dos entradas cuando, a pesar de existir afinidad semántica, pertenecen a categorías gramaticales distintas, como es el caso de conciliar $^{1}$, verbo, y conciliar $^{2}$, adjetivo, salvo que la diferente categoría sea resultado de una transposición (n. > adj.; adj. > adv.) o de sustantivaciones.

La diversidad de criterios ha llevado, pues, a una actuación heterogénea que no es exclusiva de los diccionarios del español sino que es común, al menos, en los diccionarios del inglés, del alemán, del francés y del italiano ${ }^{5}$, lo cual muestra que el lexicógrafo se mueve en un terreno inseguro que es necesario perfilar apoyándose en la semántica. A ello puede ayudar, quizás, la distinción entre variantes e invariantes de contenido.

3 De acuerdo con este criterio de relación semántica, aparecen separados tanto gentil 1 'agraciado' / gentil2 'pagano', que tienen una misma etimología como voces que tienen un origen distinto: ganga 1 'cosa que se consigue sin esfuerzo' / ganga2 'materia inservible de un mineral'.

4 Lo explican en la p. XVII del primer tomo. Esta forma de actuar les lleva a lematizar en cuatro entradas la voz real: dos para adjetivos ('verdadero', 'del rey') y dos para sustantivos ('moneda', “espacio: feria o campamento'). Lo que no es fácil de encontrar es la razón por la cual han incluido la subacepción de "(derechos) reales" en la entrada de 'verdadero' y no en la entrada de 'relativo al rey'. El DRAE-92 registra para esta voz tres entradas y otros diccionarios actuales presentan sus acepciones bajo un único lema.

5 Puede comprobarse, por ejemplo, lo ocurrido en los diccionarios de francés e italiano en Messelaar (1985). 


\section{VARIANTES E INVARIANTES DE CONTENIDO}

Los criterios expuestos no ofrecen una solución satisfactoria para la lexicografía de los casos de homonimia y polisemia. Werner (1982: 309-314) se preguntó si realmente era necesaria tal distinción. Afirmó que, desde el punto de vista teórico, se requiere tal distinción si se quiere mantener el principio o correlación "de consustancialidad entre el significante y el significado", puesto que tanto la homonimia como la sinonimia ponen en tela de juicio dicho principio; pero sostiene que no hay necesidad de seguir manteniendo este dogma porque

Al sustituir la teoría de la unidad del significante y del significado por el concepto de la atribución recíproca ${ }^{6}$ no hay por qué reunir varios sememas en un significado (tengan semas comunes o no). Entonces se pueden atribuir, en principio, varios sememas a un sólo significante, y asimismo se pueden atribuir varios significantes a un solo semema. (Werner 1982: 313).

Según Werner, renunciar a la distinción entre homonimia y polisemia supone una gran ventaja para el diccionario (semasiológico), porque permite incluir un sólo lema por significante. Con ello ya no habría términos homónimos sino sólo signos polisémicos.

A favor de la propuesta de Werner se halla el hecho de que, a excepción de los diccionarios etimológicos, no hay ninguna necesidad de representar separadamente los homónimos. Además, parece ser que esta distinción, a la que se ha dado mucho valor en el pasado, no es relevante en cuanto a las necesidades prácticas de los usuarios. Se argumenta, incluso, que la opción en favor de la polisemia beneficia la legibilidad y que es preferida por el usuario.

No obstante, argumentos semejantes se podrían presentar para defender la idea contraria que, partiendo del significante, se defendiera que sólo existen signos homónimos.

Sin embargo, en ambos casos, seguiría sin solucionarse el problema desde el punto de vista teórico, puesto que según D. Muñoz:

6 Según este concepto, significante y significado implican su existencia mutuamente. 
La solución [...] de hablar para la perspectiva onomasiológica de la descripción lingüística sólo de homonimia y para la semasiológica de polisemia, y no distinguir para una misma perspectiva entre homonimia y polisemia, lo que, si bien desde el punto de vista lexicográfico puede resultar satisfactorio, no lo es desde el punto de vista teórico, ya que esta propuesta implica que lo que es sólo un signo para el hablante, a menudo, son varios signos a la vez para el oyente, aunque el signo que recibe un oyente tiene que ser el mismo que emite un hablante (Muñoz Núñez 1999a: 106, nota 54).

Ahora bien, si hacemos caso a Trujillo, la distinción entre homonimia y polisemia no tiene en semántica ningún sentido porque se trata de un hecho inexistente al ser un mismo fenómeno lingüístico:

Homonimia -que dos signos distintos confluyan por cualquier razón histórica en un mismo significante- y polisemia -que un significante reúna bajo su expresión a varios signos distintos-son la misma cosa: todo depende del punto de vista -sincrónico o diacrónico-, no de los hechos en cuanto tales. Así, la homonimia de baca y vaca es la polisemia del significante /báka/, de la misma manera que la polisemia de dar es la homonimia del signo dar 'entregar' y del signo dar 'producir' (Trujillo 1976: 246).

El problema teórico se sitúa ahora en la distinción entre invariantes y variantes de contenido. Se habla de variantes cuando los significados tienen algún elemento semántico en común y la diferencia significativa "no conlleva un cambio de significante" (Muñoz 1999a: 312). Pastor Milán (1988: 309) señalaba ya la dificultad que existe en la práctica para “establecer en cada caso el significante en cuestión”. La propuesta realizada por Gutiérrez Ordóñez (1989: 43-56) puede ayudar a establecer el significante de cada signo

Este autor, frente a la tesis del significado único que propuso Heger (1974), plantea una distinción entre significante y expresión, apoyándose en la idea de que no es un principio demostrado que "la sustancia del significante sea exclusivamente fónica y homogénea”. Según Gutiérrez Ordóñez -que parte de la idea de Trujillo (1976: 60), quien había señalado que, además de los datos fonológicos, existen datos sintácticos y semánticos que intervienen en la diferenciación de significados-, el significante podría estar formado por una expresión sola, por una ex- 
presión más el factor $\mathrm{P}$ o sólo por el factor $\mathrm{P}$. Este factor $\mathrm{P}$ debe cumplir las condiciones de ser inmanente a la lengua y observable y tiene que ver con la valencia sintáctica, con la combinatoria semántica y con elementos de carácter formal.

Aplicando esta distinción, señala que estaríamos ante signos distintos (significantes y significados distintos) cuando, por ejemplo, cada contenido al que se asocia una misma expresión contrae relaciones de sinonimia o de antonimia con signos diferentes. Así, en los ejemplos siguientes, las expresiones /mandáR/ y /Xemélos/ formarían parte de significantes diferentes dando lugar a signos, también, distintos:

mandar $-1=$ ordenar mandar $2=$ enviar $;$ mandar $-3=$ legar

gemelos $-1=$ mellizos; gemelos -2 = prismáticos .

De acuerdo con este planteamiento y teniendo en cuenta la distinción que se hace en semántica entre invariantes y variantes de contenido, se considera que los significados asociados a una misma forma de expresión constituyen invariantes de contenido cuando concurre al menos alguno de los factores $P$ señalados.

Por su parte, Muñoz (1999a: 315), para aquellos casos que no pueden ser resueltos con criterios de "combinatoria" ha realizado una propuesta de delimitación de variantes e invariantes de contenido a partir de la frecuencia y de la generalidad de uso.

\section{CONCLUSIÓN}

Aunque se pueda discutir esta última propuesta ${ }^{7}$, será de gran utilidad para la práctica lexicográfica que la semántica, con las aportaciones de la pragmática, avance en la delimitación entre variantes e invariantes de contenido, lo cual, probablemente, permitirá no sólo superar

7 Sobre todo si se entiende que "sólo aquellas acepciones que se suponen en la competencia lingüística de todos - dada su elevada frecuencia de uso- deberían ser consignadas como signos distintos y, por lo tanto, entradas independientes" (Muñoz Núñez 1998: 186). 
el problema de la hominimia y de la polisemia en los diccionarios sino también que en ellos se presenten de forma adecuada las diferencias de contenido de una misma expresión ${ }^{8}$.

Mientras tanto, si aceptamos los últimos planteamientos expuestos, por lo menos habría que pensar en abandonar esa tendencia actual hacia una única entrada para todas las acepciones de una misma expresión y volver a establecer diferentes entradas, que se harían, por supuesto, con criterios distintos. El inconveniente, de carácter práctico, que supone el aumentar el número de entradas habría que sopesarlo con la descarga del artículo que esta decisión traería consigo, lo cual, según Zöfgen (1989), redundaría en beneficio de la accesibilidad del texto lexicográfico y sería mucho más útil para el usuario, especialmente para quien estudia un idioma como segunda lengua.

Por otro lado, habría que revisar los casos de homonimia; pero la distinción mantenida en algunos diccionarios como el DRAE entre homonimia y polisemia no sería un inconveniente sino una ventaja al facilitar la distinción de invariantes de contenido, a pesar de las lagunas y errrores etimológicos que pueden encontrarse en ellos, puesto que, como indica $\mathrm{M}^{\mathrm{a}}$ A. Pastor (1988: 307), "se supone que los signos que se comparan en la homonimia tienen su significado delimitado".

A pesar de las dificultades que encierra este planteamiento no se debe olvidar que un diccionario tendrá mayor calidad en la medida en que proporcione la mayor y más precisa información que se pueda dar en cada momento. Para ello, es imprescindible que dejen de darse la espalda la teoría semántica y la práctica lexicográfica.

8 A ello, sin duda, contribuirá la culminación del diccionario funcional que dirige M. Casas Gómez, de la Universidad de Cádiz, "donde cada significado aparezca estructurado por oposición a los demás del mismo paradigma” (D. Muñoz 1999b: 1191). 


\section{BIBLIOGRAFÍA}

CASAs, M. e I. PenadÉs, coords. (1998): Estudios sobre el Diccionario de

Uso del Español de María Moliner, Cádiz, Universidad de Cádiz.

FERNÁNDEZ GONZÁLEZ, J. et alii, eds. (1999): Lingüística para el siglo

XXI, Salamanca, Universidad de Salamanca, 2 vols.

FontAnillo, E. y M ${ }^{\text {a }}$ I. RIESCo (1998): Diccionario Escolar de la Lengua Española, Barcelona, Vicens Vives.

GutiÉRrez CuAdrado, J., dir. (1996): Diccionario Salamanca de la Lengua Española [SAlAmANCA], Madrid, Santillana.

GutiÉRREZ ORDÓÑEZ, S. (1989): Introducción a la Semántica Funcional, Madrid, Síntesis.

Haensch, G., Wolf, L., EtTinger, S., Werner, R. (1982): La Lexicografía. De la lingüística teórica a la lexicografía práctica, Madrid, Gredos.

Hausmann, F. J., Reichmann, O., Wiegand, H. y Zgusta, L. (19891991): Wörterbücher. Ein Internationales Handbuch zur Lexikographie, Berlín / Nueva York, Walter de Gruyter, 3 tomos.

Heger, K. (1974): Teoría semántica. Hacia una semántica moderna. II, Madrid, Alcalá.

LyONS, J. (1981): "Semantics", en Language and linguistics. An introduction, Cambridge, Cambridge University Press, pp. 5-36.

Maldonado, C., dir. (1997): AVANZADO. Diccionario didáctico del Español [SM-Avanzado-97], Madrid, S. M.

MesselaAr, P. A. (1985): "Polisémie et homonymie dans des dictionnaires monolingues de deux pays romans", Quaderni si semantica, 6, pp. 145-158.

Moliner, Ma (1966/1981): Diccionario de Uso del Español [DuE], Madrid, Gredos.

MuÑOZ NúÑEZ, Ma D. (1998): "Diferencias entre el DRAE y el DUE en la configuración de algunas entradas lexicográficas”, en M. Casas e I. Penadés, coords., 1998, pp. 179-190.

— (1999a): La polisemia léxica, Cádiz, Universidad de Cádiz.

— (1999b): "Criterios y dificultades para la elaboración de un diccionario funcional”, en J. Fernández González et alii, eds., 1999, pp. 1191-1197.

Pascual Rodríguez, J. A. (1996): "Derivación y diccionario. A propósito de los adjetivos activos en -dero en el DRAE", BFUCh, XXXV, pp. 349-359.

Pastor Milán, Ma A. (1988): “Un enfoque lexemático de la homonimia, 
polisemia y sinonimia", Revista Española de Lingüística, 18.2, pp. 299-316.

PAul, P. (1982): "Homonymes, Semantic divergence and Valency", Lingua, 58, pp. 291-307.

Pottier Navarro, H. (1985): La polysémie lexicale en espagnol. Théorie et résolution, París, ADEC.

QuEMADA, B. (1967): Les dictionnaires du français moderne. 1539-1863. Étude dur leur histoire, leurs types et leurs méthodes, París, Didier.

R.A.E. (1726-1732-1737): Diccionario de Autoridades, edición facsímil de 1990, Madrid, Gredos, 3 t.

(1992): Diccionario de la Lengua Española, Madrid, Espasa Calpe, $21^{\mathrm{a}}$ ed. [DRAE-92].

Rey-Debove, J. (1982): Le Robert méthodique. Dictionnaire méthodique du français actuel [RM], París.

Seco, M., Andrés, O, y Ramos, G. (1999): Diccionario del Español Actual [DEA], Madrid, Aguilar, 2 vols.

Trujillo, R. (1976): Elementos de semántica lingüística, Madrid, Cátedra.

UlLmANN, S. (1964): Language and style, Oxford, Basil Blackwell.

WERnER, R. (1982): "Homonimia y Polisemia en el diccionario", en G. Haensch et alii, 1982, pp. 297-328.

ZÖFGEN, E. (1989): "Homonymie und Polysemie im allgemeinen einsprachige Wörterbüch", en F. J. Hausmann et alii, 1989-1991, pp. 779788. 